not known. It is conceivable that the heat from the placenta on the anterior wall of a uterus might soak through a thin abdominal wall, but it is difficult to understand how thermal contours were altered by a placenta situated upon the posterior uterine wall of an obese patient with hydramnios as in Case 2. The radiator effect of the umbilicus has been mentioned, but this question remains open and is the subject of further investigation. It is just possible that the vasomotor nervous system is involved to a large extent.

\section{Summary}

The problems of placental localization and other applications of thermography are reviewed briefly to indicate the rationale of a trial of the Pyroscan and its theoretical advantages.

Cases were selected for thermographic study upon their liability to be delivered per abdomen. From 47 cases studied 13 came to section and the accuracy of predictions is assessed and discussed.

A basic description of the Pyroscan is given, and experimental methods and conditions are described.
Interpretation of thermographs of the pregnant abdomen is discussed with reference to the thermal contours of nonpregnant controls.

The results showed that the site of functional placental tissue could be accurately predicted in one plane in all the cases that came to section.

I am indebted to Mr. J. R. Hassard and Mr. J. R. Saunders, consultant obstetricians, for their enthusiastic help and the reference of their patients; to Mr. C. Maxwell Cade, chief research engineer (infra-red) for S. Smith and Son Ltd., for his technical advice; and to the directors of S. Smith and Son Ltd. for loan of the apparatus.

\section{REFERENCES}

Barnes, R. B. (1963). Science, 140, 870.

Browne, J. C. M., and Veall, N. (1953). F. Obstet. Gynaec. Brit. Emp., 60, 141 .

Donald, I. (1964a). Practical Obstetric Problems, p. 317. Lloyd-Luke,

London.

Hibbard, B. M. (1962). Proc. roy. Soc. Med., 55, 640.

Lawson, R. N. (1956). Canad. med. Ass. 7., 75, 309.

Lloyd Williams, K., and Cade, C. M. (1964). Med. biol. Ill., 2, 105.
Lloyd Williams, F., and Handley, R. S. (1960). Lancet, 2, 958. - Lloyd Williams, F., and Handley,

\title{
Protection of Mice by Interferon Against Systemic Virus Infections
}

\author{
N. B. FINTER,* M.B., B.CHIR., M.R.C.P.
}

Brit. med. F., 1964, 2, 981-985

Many workers have described inhibition by interferon of the growth of viruses in tissue culture cells. In comparison there are only a few references to effects of interferon in animals. These for the most part have described prophylactic effects against a local infection with a virus subsequently inoculated into the same anatomical site. Experiments are here described in which potent preparations of mouse interferon injected subcutaneously or intramuscularly protected mice against intraperitoneal infections with encephalitis viruses.

\section{Materials and Methods}

Viruses. - The MB strain of Semliki Forest virus has been described elsewhere (Finter, 1964a). Encephalomyocarditis (EMC) virus was obtained from Dr. E. M. Martin, National Institute for Medical Research, and passaged in L cell-tissue cultures. West Nile virus was obtained from Dr. J. S. Porterfield, National Institute for Medical Research, and passaged in the brains of mice.

Interferon.-This was prepared from the brains of mice infected with West Nile virus. A $10 \%(w / v)$ suspension of infected brains was made in Hanks's saline, and twice centrifuged at $79,000 \mathrm{~g}$ to sediment virus particles. The final

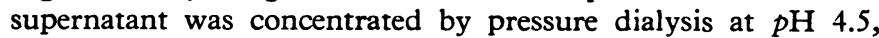
at which level some inactive protein precipitated (A. Davies, personal communication). The $\mathrm{pH}$ was adjusted to 7 , and the material was clarified by low-speed centrifugation. The final products, in which no infective virus could be detected, contained about 40,000 units of interferon per ml., as measured

* Research Department, Imperial Chemical Industries Limited, Pharmaceuticals Division, Alderley Park, Macclesfield, Cheshire. in vitro by the quantitative haemadsorption assay technique (Finter, 1964b). Control preparations of uninfected normal mouse brains were made by the same method. Fuller details of these preparations will be given elsewhere.

Protection Experiments.-Various doses of interferon and times of administration were tested. Groups of 10 male mice (15-20 g.) were used for each treatment, the weights of all mice in an experiment being within a 2-g. range. Mice were dosed with interferon by the intramuscular route $(0.1 \mathrm{ml}$.) or by the subcutaneous route $(0.2 \mathrm{ml}$.). Viruses were inoculated by the intraperitoneal route $(0.2 \mathrm{ml}$. per mouse). In each experiment the challenge virus was titrated in parallel, and the actual dose used for challenge was calculated. Cages were inspected at 9 a.m. and 5 p.m. each day. For purposes of calculation, mice found dead-for example, at 9 a.m. on the fifth day after virus infection-were assumed to have died at 5 days. Additional mice dying up to $5 \mathrm{p} . \mathrm{m}$. on the same day were assumed to have died at $5 \frac{1}{2}$ days. Protection conferred by interferon was shown by an increase in the number of mice surviving infection or by a prolongation in the survival time as compared with control mice. The mean of the reciprocals of the days of death (M.R.D.D.) for all mice in a group was calculated. The longer the average period of survival in a group of mice the smaller the value for the M.R.D.D. Differences between the M.R.D.D. values for different groups were tested for significance.

Statistics.-It was found that the reciprocal of the day of death was normally distributed, and therefore this transformation was adopted for analysis. Because mice in some groups survived the virus infection the distribution was truncated, and the technique of Gupta (1952) was used to estimate the means and their corresponding standard deviations. The mean value 
for the standard deviation in 45 groups of treated and control mice was 0.03 . Using this, differences between the M.R.D.D. values obtained with different treatments were tested for significance, employing the t-test. Since we were interested in testing the degree of protection obtained, the single-sided t-test was used for differences between the M.R.D.D. values of control and treatment groups. For comparison between different interferon treatments, the two-sided t-test was used. In these experiments a difference between the M.R.D.D. values in two groups of 10 mice was significant at the $10 \%$ level in the single-sided test if it exceeded a value of 0.0178 , and at the $5 \%$ level if it exceeded 0.0235 . The corresponding significant differences for two-sided tests were 0.0235 and 0.0288 respectively.

\section{Results}

The protective effect of interferon was studied in experiments of two types. Either encephalomyocarditis virus (EMC) or Semliki Forest virus (SF) was used for challenge. When injected into the peritoneum these viruses gain access to the central nervous system and cause a rapidly fatal encephalitis.

In the first type of experiment mice were challenged with between 5 and 56 lethal doses $\left(\mathrm{LD}_{50}\right)$ of EMC. Interferon treatment led to an increase in the number of mice surviving after virus infection and to an increase in the mean period of survival. For statistical analysis of the significance of differences between the results in different experimental groups the M.R.D.D. was calculated for each group as described above.

A typical experiment is illustrated in Fig. 1. Groups of 10 mice received four doses of 7,600 units of interferon by intramuscular injection 20 and $3 \frac{1}{2}$ hours before challenge with EMC, and 20 and 44 hours after challenge. Other mice received processed normal mouse brain at the same time, and control mice received no treatment. Mice were challenged with either 14 or 56 lethal doses of EMC virus by intraperitoneal inoculation, and were observed twice daily for 21 days. Nine out of 10 of the control mice were dead by the fifth day after infection with either $56 \mathrm{LD}_{50}$ or $14 \mathrm{LD}_{50}$ of virus. Treatment with normal mouse brain appeared to give no protection, a finding confirmed by statistical analysis (M.R.D.D. $=0.296$ for control group ; M.R.D.D. $=0.265$ for mice treated with normal mouse brain). In contrast, the interferon treatment completely protected mice against $14 \mathrm{LD}_{50}$ of virus, and 5 mice out of 10 survived indefinitely after $56 \mathrm{LD}_{50}$, with a highly significant increase in the mean survival time of the group (M.R.D.D. $=0.096$ ).

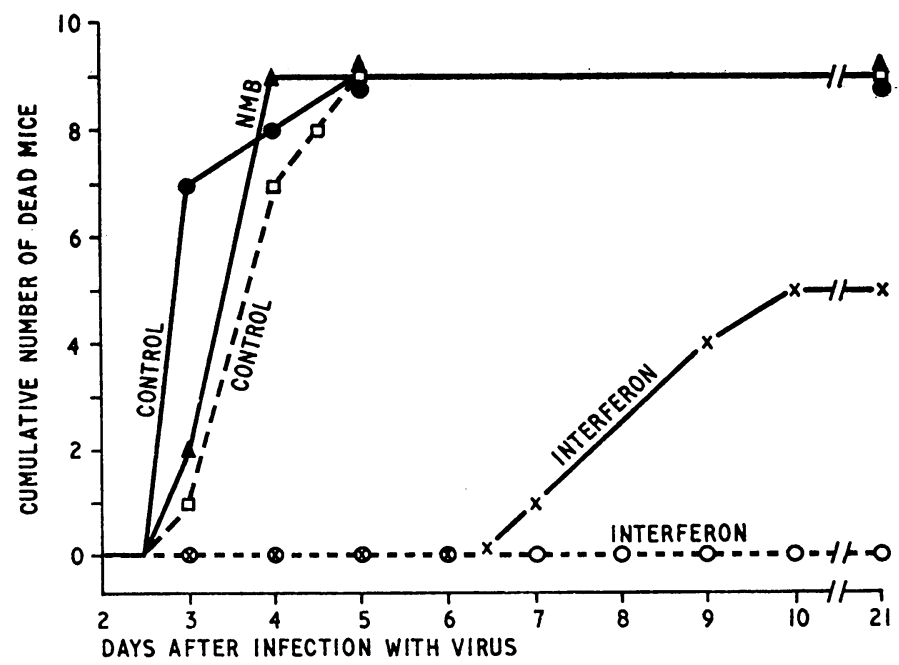

FIG. 1.-Protection of mice against EMC virus by mouse interferon. Groups of mice received two doses of interferon (7,600 units) or normal mouse brain (NMB) before and after infection with EMC. Control mice were untreated. Broken lines $=14 \mathrm{LD}_{\mathrm{s0}}$ of $\mathrm{EMC}$. Continuous
In the second type of protection experiment mice were challenged with 1,200-21,500 $\mathrm{LD}_{50}$ of SF. Even with interferon treatment, only a few mice survived these very large doses of virus, but the interferon led to significant increases in the period of survival. A typical experiment, shown in Fig. 2, is described in a later section.

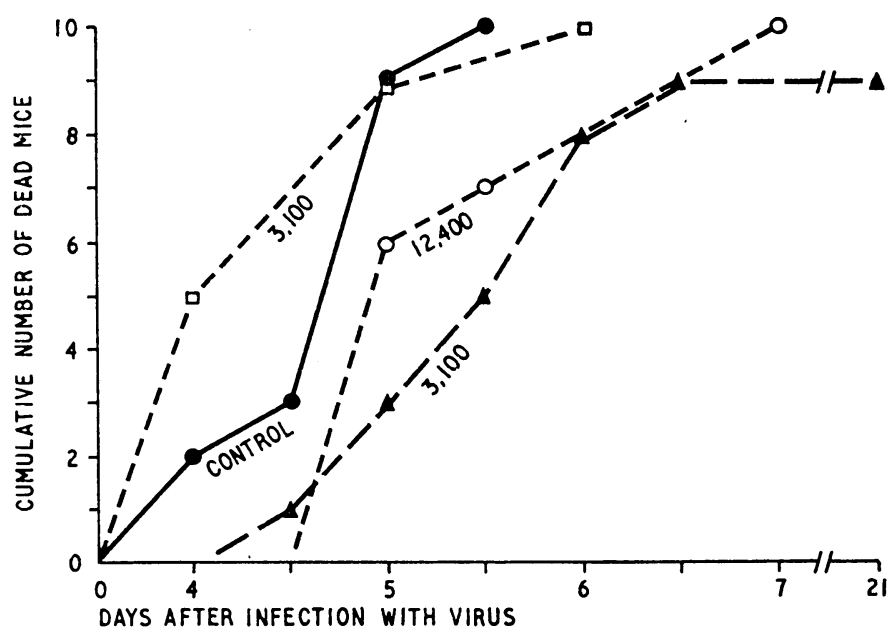

FIG. 2.-Prolongation of survival of mice infected with Semliki Forest virus $\left(21,500 \mathrm{LD}_{\mathrm{so}}\right)$ by a large amount of interferon injected three hours virus $\left(21,500 \mathrm{LD}_{\mathrm{so}}\right)$ by a large amount of interferon injected three hours
later. Figures refer to number of units of interferon injected. $O=\mathrm{Un}$ treated control mice. $\square \bigcirc=$ Interferon injected three and a half hours after virus. $\Delta=$ Interferon injected three hours before virus.

\section{Specificity of Effect of Interferon}

A virus inhibitor present in extracts of normal monkey brain but with properties quite different from those of interferon has been described (Baron, Friedman, and Buckler, 1963). In the experiment shown in Fig. 1 mice dosed with normal mousebrain extract died at the same rate as untreated controls. In two further experiments dosing of mice with normal mousebrain extracts conferred no significant protection on them against infection with virus under circumstances where interferon preparations did. It is thus concluded that the protective effect of the interferon preparations used was not due to the normal mouse-brain materials present in them.

\section{Dose of Interferon}

Three groups of 10 mice were dosed with dilutions of an interferon preparation by subcutaneous injection 24 hours and $3 \frac{1}{2}$ hours before infection with $20 \mathrm{LD}_{50}$ of EMC virus, and 21 hours and 48 hours after infection. One group received 6,400 units of interferon at each time, another group 1,600 units, and the third group 400 units. Mice were observed as usual for deaths. Results of this experiment are shown in Fig. 3. All control mice were dead on the seventh day after infection (M.R.D.D. =0.205). Five of the mice which received the largest dose of interferon survived, and the lives of the other five were significantly prolonged (M.R.D.D. for this group $=0.099$ ). Nine mice died out of the 10 that received 1,600 units of interferon. Nevertheless this dose of interferon still conferred some protection on the mice, as shown by a significant increase in the period of survival (M.R.D.D. $=0.162$ ). However, a dose level of only 400 units of interferon conferred no significant protection (M.R.D.D. $=0.218$ ) even though one mouse survived infection. Thus the interferon preparation used in this experiment could not be diluted much more than fourfold before its protective effect was lost.

In another experiment mice received a single dose of interferon by the intramuscular route 20 hours before infection with $80 \mathrm{LD}_{50}$ of SF. A dose of 15,000 units conferred a 
highly significant degree of protection (M.R.D.D. $=0.131$; M.R.D.D. for controls $=0.162$, but a dose of 5,000 units gave no significant protection (M.R.D.D. $=0.158$ ).

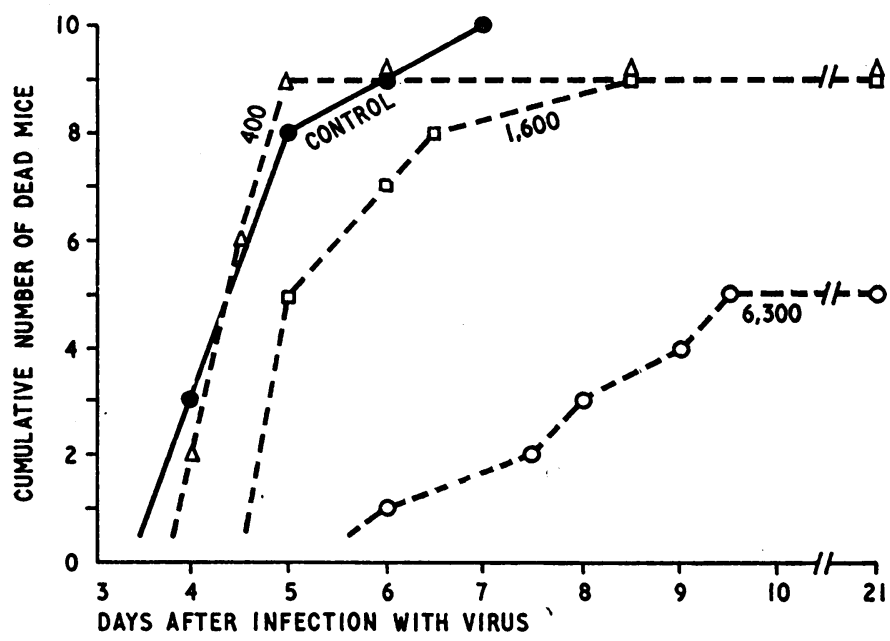

Fig. 3.--Amount of interferon needed to protect mice against intraperitoneal infection with 20 LD of EMC virus. Mice received four peritoneal infection with 20 of
inoculations of the amounts of interferon shown. Control mice were
untreated.

\section{Route of Administration}

Three groups of mice received doses of 1,600 units of interferon either by intramuscular or subcutaneous injection, or with the dose divided equally between the two routes. Two doses were given before challenge with $20 \mathrm{LD}_{50}$ of EMC and two doses after challenge. Results are shown in Fig. 4. Mice which received interferon by the intramuscular route fared best, and only five died (M.R.D.D.=0.123). Interferon injected subcutaneously was the least effective, with only one mouse surviving. The M.R.D.D. value of 0.162 was significantly worse than after intramuscular dosing, though still significantly better than in untreated controls (M.R.D.D. =0.205). When interferon was administered half by each route, intermediate results were obtained (M.R.D.D.=0.137). In subsequent experiments interferon was injected by the intramuscular route.

\section{Time of Administration of Interferon}

In tissue-culture experiments with mouse-brain interferon and mouse fibroblast cells it has been found that there is little

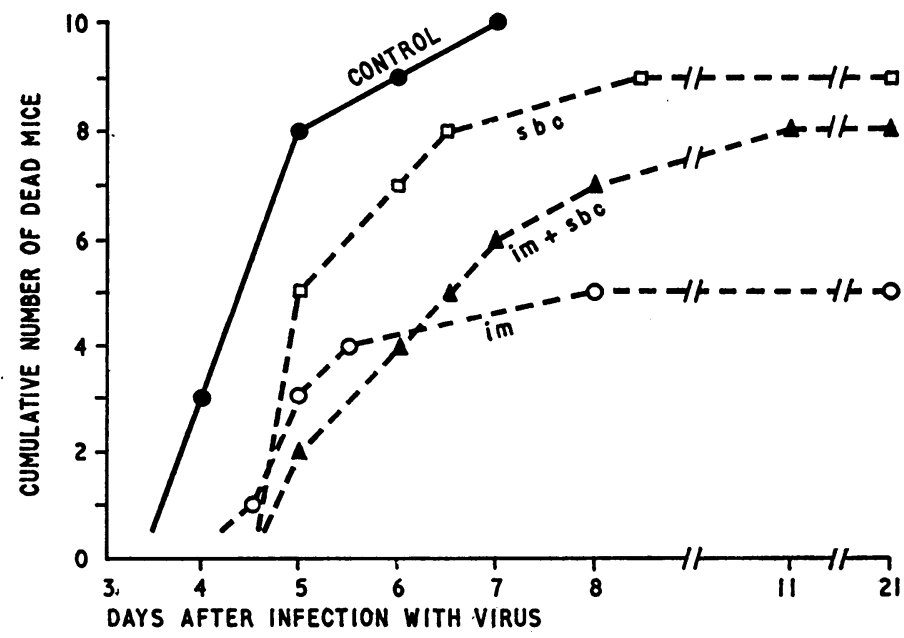

FIG. 4.-Protection conferred by interferon administered by different routes. Groups of mice received four doses of 1,600 units of interferon by the intramuscular (im) or the subcutaneous (sbc) route, or by both routes $(\mathrm{im}+\mathrm{sbc})$. Controls were untreated. Mice were challenged with 20 LD, of EMC virus. protective effect if the interferon and cells are in contact for only one hour for challenge with virus, but after contact for three hours the effect is about $35 \%$ of the maximum (Finter, 1964b). In animal experiments some time must also be required for injected interferon to reach the cells to be protected. In tissue-culture experiments the effects of interferon have been shown to wane after some days (Isaacs and Westwood, 1959b ; Paucker and Cantell, 1963), and this must also happen in animals. Thus there is likely to be an optimum time or period during which administration of a single dose of interferon will produce its greatest effect.

In four experiments a single dose of interferon was given at a number of different times between 48 hours and 15 minutes before challenge with SF or EMC. Results of one such experiment are shown in the Table. A single dose of 3,100 units of interferon gave no significant protection compared with the controls when injected 48 hours before challenge with 2,400 $\mathrm{LD}_{50}$ of $\mathrm{SF}$, and gave an effect which was only just significant at the $10 \%$ level when injected one hour before challenge.

Protection Conferred by Interferon Inoculated at Different Times Before

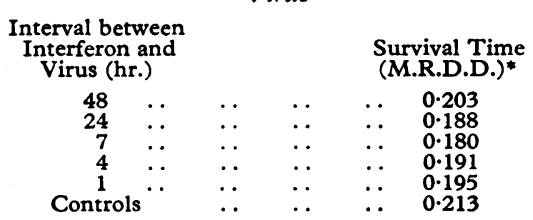

Mice received a single injection of 3,100 units of interferon at the indicated times before challenge with 2,400 LD 50 of Semliki Forest virus. Controls received no interferon.

* M.R.D.D. = Mean reciprocal day of death. A difference of 0.0235 between the M.R.D.D. values in the controls and a treatment group is significant at the $5 \%$ level,
and of 0.0178 at the $10 \%$ level.

When the interval between interferon and challenge was 24, 7 , or 4 hours there was significant protection. This appeared greatest with the seven-hour interval, but the differences between the results at these three times are not statistically significant. In the three other experiments significant protection was similarly obtained with single doses of interferon administered at various times between 30 hours and $3 \frac{1}{2}$ hours before inoculation of challenge virus, but again the results allowed no closer definition of an optimum period for dosing within these limits. No significant protection was conferred by doses of interferon of up to 15,000 units per mouse given 48 hours before virus.

\section{Effect of Dosing with Interferon after Virus}

In the three experiments additional doses of interferon given 20 and 44 hours after virus infection to mice which had received adequate interferon treatment before challenge led to no improvement in the protection.

In the experiment illustrated in Fig. 2 three groups of mice were infected with $21,500 \mathrm{LD}_{50}$ of SF. Three hours later one group was injected with 3,100 units of interferon and another with 12,400 units. All the mice died within seven days. However, mice treated with the larger dose of interferon survived significantly longer (M.R.D.D. $=0.185$ ) than the controls (M.R.D.D. $=0.210$ ), whereas the smaller dose of interferon had no protective effect (M.R.D.D.=0.230). For comparison of the effect of dosing before and after virus challenge it may be noted that another group of mice in the same experiment received 3,100 units of interferon three and a half hours before challenge and had an M.R.D.D. of 0.179.

Comparable results were obtained in a second experiment. Mice were infected with $80 \mathrm{LD}_{50}$ of SF. The M.R.D.D. for controls was 0.162 . Mice that received 15,000 units of interferon by intramuscular injection three hours after challenge outlived the control mice by a period which was just significantly longer (M.R.D.D.=0.144), but the effect of the inter- 
feron was much smaller than when the same dose was given 21 hours before virus inoculation (M.R.D.D. $=0.130$ ).

\section{Discussion}

In spite of many difficulties which remain to be solved it is possible that interferon may one day find some place in clinical medicine. The results described here are of interest in this respect. It has been demonstrated that adequate doses of interferon injected into an animal can reach cells at a remote site and decrease their susceptibility to subsequent virus infection. Interferon was injected intramuscularly or subcutaneously and protected mice against encephalitis viruses inoculated by the intraperitoneal route. Although protective effects of interferon in animals have previously been described, in most of the experiments the interferon was injected at the same site as the challenge virus. Thus rabbits (Isaacs and Westwood, 1959a ; Nagano and Kojima, 1958), monkeys (Andrews, 1961), and human volunteers (Scientific Committee, 1962) have been protected against infection of the skin with vaccinia virus by interferon injected previously into the same site. Similarly, the eyes of rabbits have been protected against vaccinia virus (Cantell and Tommila, 1960). Denys (1963), however, was able to protect rats against virus infections by interferon injected into another site. In his experiments sixday-old rats were protected against a subcutaneous infection with $10 \mathrm{TCD}_{50}$ of Sindbis virus when interferon was inoculated 12 hours before and at 24-hourly intervals after the virus. The interferon was obtained from tissue cultures of neoplastic rat cells treated with Sindbis virus. To produce such remote effects with interferon, as in his experiments and those reported in the present paper, is obviously more difficult than to provide local protection of cells against virus infection, but it is a problem much more relevant to practical aspects of virus prophylaxis and therapy.

During their preparation the infected brain extracts used as a source of interferon were twice subjected to a centrifugal force more than sufficient to sediment virus particles. The final preparations contained no detectable infectious virus, and their titres were not changed if they were incubated with a hyperimmune serum to West Nile virus before in vitro assay. Thus infectious or inactivated virus was not responsible for their antiviral activity. It has also been shown that the protective effects in mice were not due to viral inhibitors present in normal mouse-brain extracts. On the other hand, the antiviral properties of the extracts, such as resistance to treatment at $p \mathrm{H} \mathrm{2,}$ sensitivity to trypsin, wide spectrum of antiviral activity, and species specificity, which will be described fully elsewhere, resembled those described for other interferons. Thus there seems no reasonable doubt that the antiviral effects of the extracts in vitro and in vivo were in fact due to interferon present in high concentration, though obviously in a very impure form. It may be noted that we have also prepared interferon by treating tissue cultures of $\mathrm{L}$ cells with Newcastle disease virus. After this had been considerably concentrated it protected mice in similar experiments and to an extent proportional to its interferon content as measured in vitro. It seems unlikely that common antiviral factors other than interferon would be present in both this type of preparation and the brain extracts.

Large amounts of interferon were needed to produce the effects described in the present paper. Data to be presented elsewhere show that the preparations of mouse interferon used in the present experiments were 10 to 100 times more potent than those obtained from a variety of other mouse tissues in vivo or in tissue culture. Nevertheless even these comparatively very potent preparations contained little more interferon than that required to protect mice: in the experiment shown in Fig. 3 the interferon preparation used gave no protection to mice when it had been diluted 16 times. Thus the reason why protective effects have usually been demonstrated with interferon preparations in vivo only under the particularly favourable conditions of local prophylaxis may be that the preparations available have contained inadequate amounts of interferon.

Friedman and Rabson (1964) injected newborn mice subcutaneously with a strain of polyoma virus. This led to the appearance five days later of readily detectable levels of interferon in the tissues of the mice. They challenged such mice on the fifth day with $6,300 \mathrm{LD}_{50}$ of EMC virus. Control mice which had not been previously infected with polyoma all died by the third day after challenge. In contrast, mice previously infected with polyoma virus were strikingly protected, with 8 out of 16 surviving EMC infection. It is interesting to compare these results with those obtained in the present experiments with injected interferon but with much smaller doses of EMC. If the protective effects of polyoma virus are entirely due to the production of endogenous interferon in the infected mice, then the amounts so produced may well be much larger than those which were injected in the present experiments. It may be noted that the largest single dose injected into a mouse was 15,000 units, which is slightly less than the total interferon obtained from the brain of one mouse infected with West Nile virus (average 17,000 units).

Interferon was most effective when it was given prophylactically and when mice were adequately treated before infection with virus; no additional protection was conferred by interferon given after infection. However, in two experiments a single large dose of interferon injected three hours after infection with SF significantly protected mice. From results in tissue-culture experiments it seems clear that interferon injected at this time will not have modified the growth of virus in those cells infected by the original inoculum. These cells will therefore have released newly formed virus in large quantities from the fourth or fifth hour after infection. But interferon injected after three hours will still be able to reduce the susceptibility to virus infection of those cells which would otherwise have been infected by the newly released virus. Thus a delay in the time of administration of interferon is equivalent to the injection of a much larger dose of challenge virus. It will be seen from Fig. 1 that the same dose of interferon was much less effective against $56 \mathrm{LD}_{50}$ than against a four times smaller dose.

The duration of the protection conferred by a single dose of interferon has not been closely defined from the present experiments. Protective effects were obtained from one dose of interferon given up to 30 hours before challenge with virus, but not from interferon given 48 hours before virus. We have found that local protection by interferon of the skin of a rabbit against subsequent challenge with vaccinia virus waned considerably after four days, and vanished completely after seven days (unpublished experiments).

In conclusion, it should be emphasized that the preparations of interferon from the brains of mice used in the present study could not be used safely for any purpose in human beings, and in any event would not be expected to produce any significant protective effects in them.

\section{Summary}

Mice have been protected against intraperitoneal infection with encephalomyocarditis virus (EMC) and Semliki Forest virus $(\mathrm{SF})$ by subcutaneous or intramuscular inoculation of mouse interferon. Protection was shown by an increase in the number of mice surviving infection or as an increase in the mean period of survival after infection.

Large amounts of interferon (3,000-5,000 units, as measured in vitro) were required to protect a mouse under the conditions 
of these experiments. Better results were obtained when the interferon was injected by the intramuscular route.

A single dose of interferon afforded protection to mice when injected at times between 30 and $3 \frac{1}{2}$ hours before infection with virus, but not when given 48 hours before infection. Some protection was obtained when a large dose of interferon was given three hours after infection.

I am grateful to Dr. O. L. Davies for advice on the statistical aspects of this work. Thanks are also due to Miss B. Brocklehurst for invaluable technical assistance.
REFERENCES

Andrews, R. D. (1961). Brit. med. F., 1, 1728.

Baron, S., Friedman, R. M., and Buckler, C. E. (1963). Proc. Soc. exp. Biol. (N.Y.), 113, 107.

Cantell, K. and Tommila, V. (1960). Lancet, 2, 682

Denys, P. (1963). Ibid., 2, 174

Finter, N. B. (1964a). \%. Hyg. (Camb.), 62, 337.

- (1964b). Virology. In press.

Friedman, R. M., and Rabson, A. S. (1964). F. exp. Med., 119, 71

Gupta, A. K. (1952). Biometrika, 39, 260.

Isaacs, A., and Westwood, M. A. (1959a). Lancet, 2, 324.

- (1959b). Nature (Lond.), 184, 1232.

Nagano, Y., and Koiima, Y. (1958). C.R. Soc. Biol. (Paris), 152, 1627

Paucker, K., and Cantell, K. (1963). Virology, 21, 22

Scientific Committee on Interferon (1962). Lancet, 1, 873.

\title{
Neurogenic Intermittent Claudication
}

\author{
JOHN GRIMLEY EVANS,* M.B., M.R.C.P.
}

Brit. med. F., 1964, 2, 985-987

Intermittent claudication, pain in the legs produced by exercise and relieved by rest, is a well-known manifestation of peripheral or aorto-iliac obstructive vascular disease. It may also be a prominent feature of anaemia, McArdle's (1951) disease, the pre-infarctive anterior tibial syndrome (French and Price, 1962), and as a complication of vasoconstrictive drugs (Graham, 1960). It is less well known as a symptom of a "neurological" lesion.

Lewtas and Dimant (1957) described the case of a man of 62 with an eight-year history of pain, numbness, and tingling in the legs produced by exercise associated with hypertrophic interstitial polyneuritis (Dejerine-Sottas disease) of the cauda equina. Blau and Logue (1961) described a similar symptomcomplex occurring in six patients with midline protrusions of a lumbar disk with an associated arachnoiditis. Four similar cases have been seen in the departments of neurology and neurosurgery of the United Oxford Hospitals within a yearthree with a protrusion of a lumbar disk and one with an

\begin{tabular}{|c|c|c|c|c|}
\hline \multicolumn{5}{|c|}{ C.S.F. Findings ${ }^{1}$} \\
\hline & & & $\begin{array}{c}\text { Protein } \\
(\mathrm{mg} . / 100 \mathrm{ml} .)\end{array}$ & $\underset{\text { (per ml.) }}{\text { Cells }}$ \\
\hline $\begin{array}{l}\text { Case 1 } \\
\text { Case 2 } \\
\text { Case 3 } \\
\text { Case 4 }\end{array}$ & $\begin{array}{l}\ldots \\
\therefore \\
\therefore\end{array}$ & 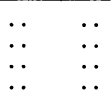 & $\begin{array}{r}180 \\
70 \\
? \\
110\end{array}$ & $\begin{array}{r}8 \\
0 \\
37 \\
0\end{array}$ \\
\hline
\end{tabular}

${ }^{1}$ All samples obtained above the level of myelographic obstruction.

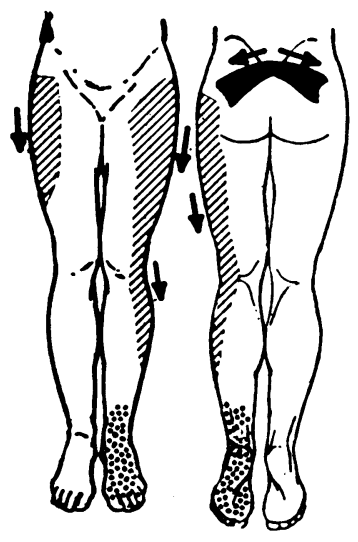

CAsE 1.

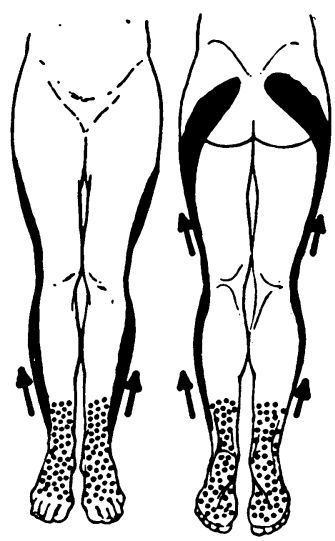

CASE 2.

adhesive arachnoiditis of the cauda equina without a disk lesion.

The distribution of symptoms in the four men and the C.S.F. findings are summarized in Fig. 1 and the Table; only one of the cases is reported in detail.

\section{Case 2}

A 60-year-old yarn-spinner presented with a four-year history of cramp-like pain in the antero-lateral aspects of his legs brought on by walking. Initially the pain would occur after a quarter of a mile ( 400 metres) of moderate walking, but by the time of admission he could only walk 200 yards (180 metres) before the pain became so severe that he was forced to stop. If he then stood still the discomfort would diminish in a quarter of an hour. The story seemed so suggestive of vascular insufficiency that his general practitioner had treated him with tolazoline hydrochloride for a year without success. Six months before admission he noticed pinsand-needles in both feet associated with the pain in the legs. There had been no sphincter disturbance, and there was no history of lumbago, back injury, or sciatica.

On examination all peripheral pulses were of good volume and remained so after sufficient exercise to bring on the pain. There was diminished power of dorsiflexion of the left foot, more noticeable after exercise. The left knee-jerk was less brisk than the

* Lately Senior House Officer, Department of Neurology, Churchill Hospital, Oxford.

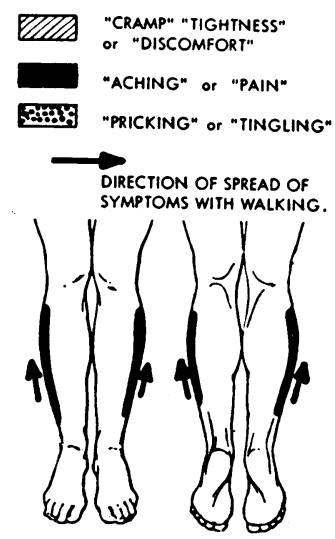

CASE 3.

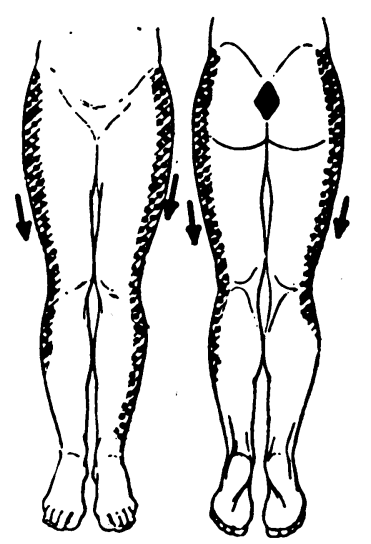

CASE 4.

Fig. 1.-Distribution of symptoms 